\title{
THE ELABORATION OF THE METHOD OF FATIGUE TESTING OF THE ROTOR OF THE MOSUPS PLANE PROPULSION SYSTEM
}

\author{
Dominik Glowacki \\ Mirosław Rodzewicz \\ Warsaw University of Technology, Institute of Aeronautics and Applied Mechanics \\ Nowowiejska 24, 00-665 Warsaw \\ dglowacki@meil.pw.edu.pl, miro@meil.pw.edu.pl
}

\begin{abstract}
This paper concerns fatigue testing of the rotor of the propulsion system for the MOSUPS - an unmanned aircraft designed in a joint wing configuration, and equipped with a ducted propeller. The work presents the analysis of the stresses and deformations of the rotor structure as well as the form of the loading cycle. The aim of the paper is to introduce the concept of a simplified method of fatigue testing of multi-blade rotors. With the sophisticated geometry of the rotor in mind - the authors applied the FEM tools and implemented the ANSYS and nCode programs. The prototype of the fatigue stand built by the authors is also presented in the paper.
\end{abstract}

Keywords: UAV, Propulsion system, Stress analysis, Fatigue tests.

\section{INTRODUCTION}

There were the real life cases of rotor failures that motivated the authors to investigate the problems associated with fatigue testing of the ducted propeller rotor (ducted prop). For example, a common problem is the abrasion of the blade tips by the duck walls due to vibrations caused by insufficient mass balancing or the resonance oscillations of the duck.

The goal of this paper is to introduce the concept of the fatigue testing method and analyse of the fatigue durability of the ducted propeller for the MOSUPS unmanned aircraft (Fig. 1.). This plane was built by the consortium composed of the Institute of Aviation, the Warsaw University of Technology, MSP Marcin Szender company, and the Airforce Institute of Technology. The main feature of the MOSUPS is an innovative joint-wing configuration, which reduces inductive drag of the plane [1, 2, 3]. The project was sponsored by the National Center of Research and Development within the program of applied R\&D investigations PBS1/A6/14/2012.
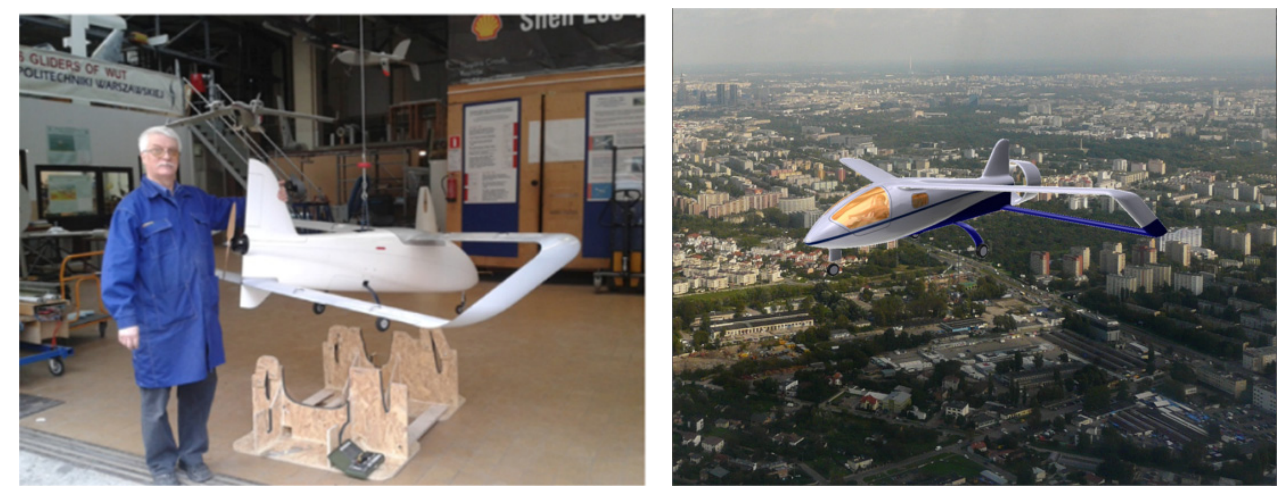

Fig. 1. Aircraft MOSUPS of joint-wing configuration 
Besides applying a joint-wing configuration, one of the main purposes of the project was to use a ducted composite propeller as the propulsion system. The rotor of the ducted propeller is powered by a $3 \mathrm{~kW}$ electric engine Rotomax 1.6, and consists of a CFRP-hub and 5 CFRP-blades. The nominal rotation speed is about 8000 RPM. It is high enough to induce relatively high loads generated both by aerodynamic forces and mass forces. It is necessary to emphasize that in the rotor structure there are glued joints between the hub and the blades. Due to the strength degradation processes of the glue caused by fatigue loads, these joints may be concerned as the weak-points of the rotor structure and, therefore, they should be fatigue proved. As the rotor is manually manufactured some dissipation of the strength properties of any blade-joint is possible. It is, therefore, worth checking all blade-joints by simultaneously subjecting them to identical load cycles.

The authors propose a significant simplification of the rotor's loading system on the fatigue stand. It is suggested that the loads are induced by fixing all the blade tips to the stationary stand and applying a single force introduced perpendicularly in the central point of the hub instead of by applying revolutions to the rotor (which may be dangerous in case of high RPM). In order to fix the blades the researchers applied special composite extensions with a tuned stiffness, which are glued to the blade-tips, and from the other side are anchored to a stiff metal ring (aluminum car-rim was applied - see Fig. 2.). The load at the central point of the hub was introduced by a pneumatic actuator. Such a loading system causes all the blades to be simultaneously tensioned and bended, making it possible to simulate on the stand not only centrifugal forces but also the bending effect of the aerodynamic forces. The biggest challenge in applying this simplified loading system is estimating a load which is equivalent to the real load of a rotating prop. The FEM analysis was found very useful in solving this problem. Another problem to be solved was an actuating system including both: technical realization (see Fig. 3.) and the software for the load control. These problems are described below.
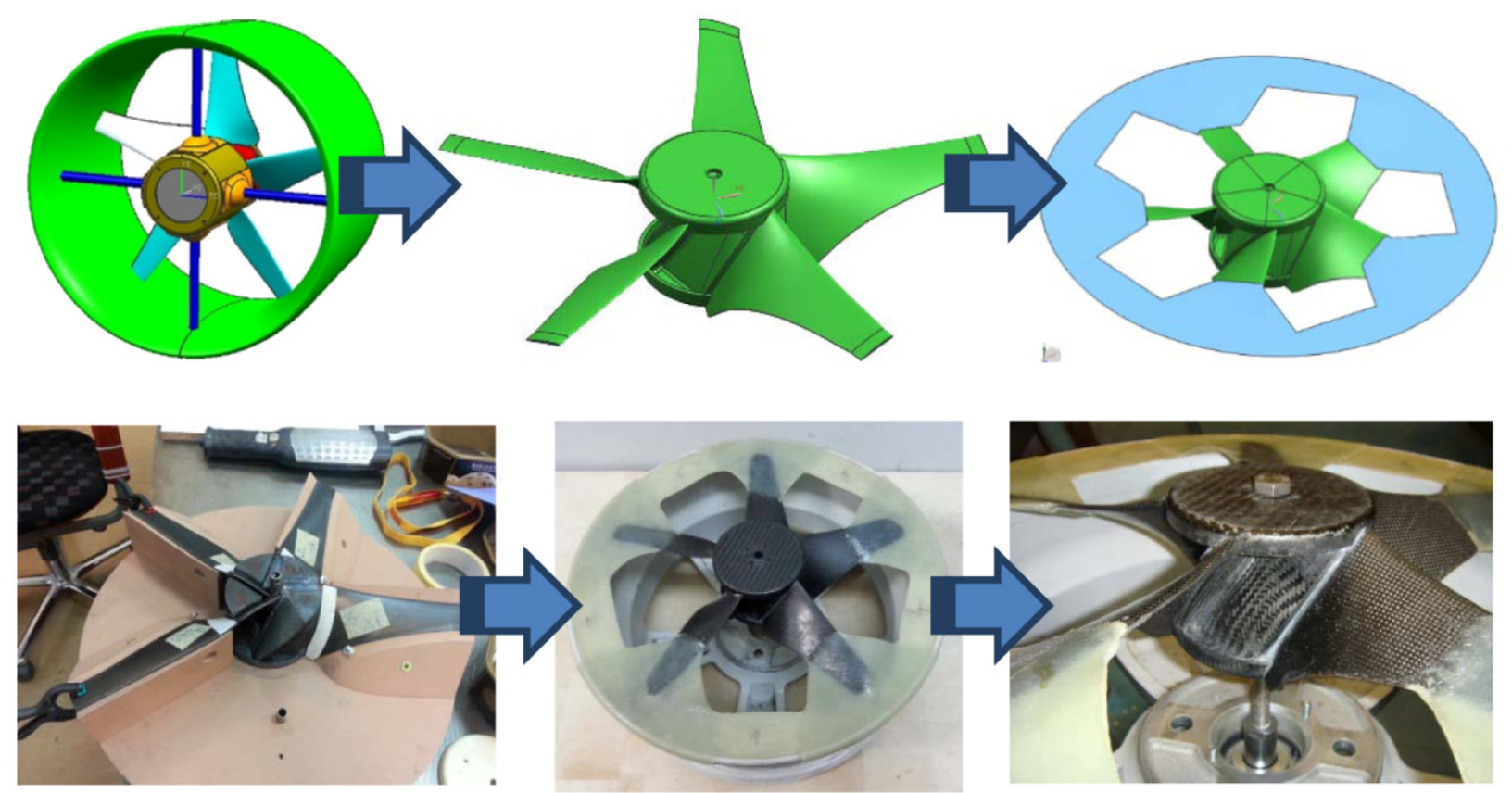

Fig. 2. Ducted propeller and the details of the specimen used for testing fatigue durability 


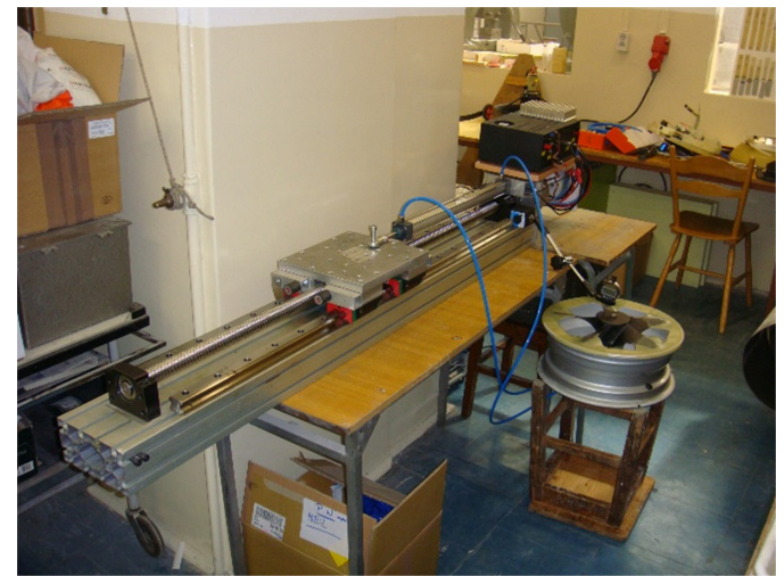

Fig. 3. The fatigue stand for the rotor of the MOSUPS propulsion system

\section{THE PLAN OF INVESTIGATIONS}

As it was mentioned above the main problem was estimating the equivalent load value for the implementation of the simplified fatigue test of the rotor-specimen. The following tasks were undertaken to solve this problem:

○ Numerical simulations of the stresses and deformations of the rotating propeller as well as stresses and deformations of the rotor-specimen under load applied using the method of simplified fatigue testing

○ Experimental investigations.

\section{NUMERICAL SIMULATIONS}

The first stage of the work was preparing the numerical model of the rotor for calculations. For this purpose, the HyperMesch program was used.

The researchers built a cyclic-symmetrical model of the rotor consisting of shell elements having linear functions of the shape. At the points of cross-sections the boundary conditions were applied to simulate periodicity. Then inertial loads (generated by rotational speed of $8000 \mathrm{RPM}$ ) were applied. The mesh of the rotor FEM model is shown in figure 4. This model was later exported to the ANSYS program, for making the appropriate static analysis.
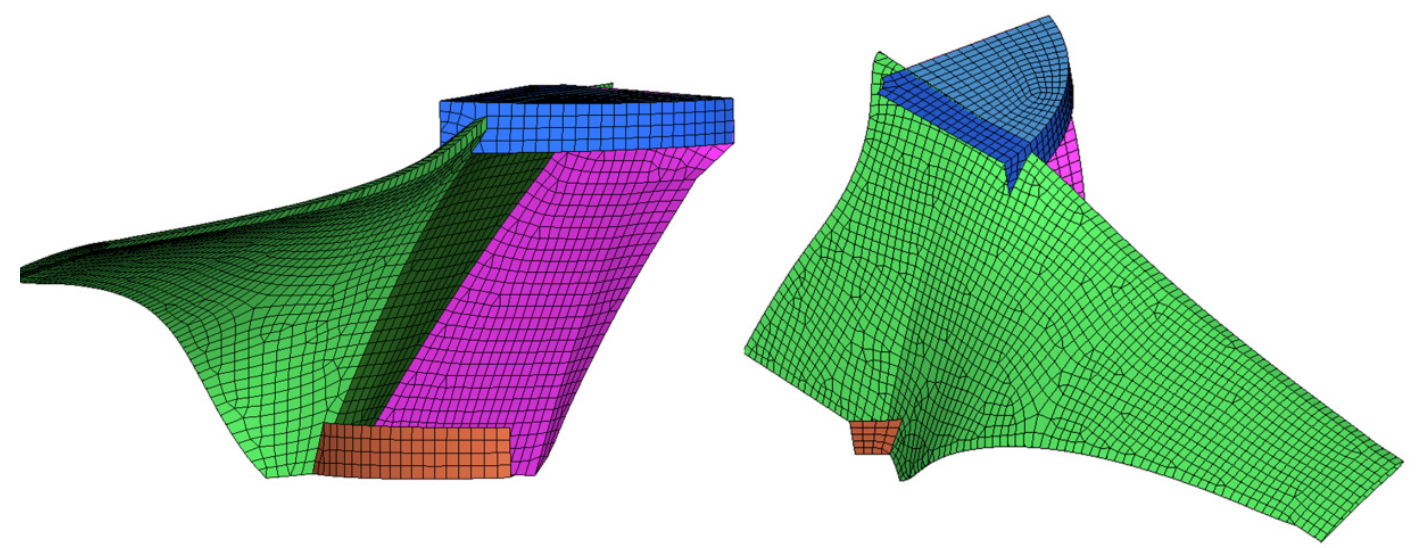

Fig. 4. The mesh of the rotor FEM model

At first it was checked what stresses existed in the blade for maximum value of rotational speed and what values appeared in the joints of the blade with the hub (Fig. 5.). As the main loading on the fatigue stand was planed the single force applied at the central point of the hub - there were 
checked the stresses for the unitary force, when the blade-tips are fixed to the stand (Fig. 6.). On this basis it was possible to calculate an equivalent load that gives the stress level in the blade-hub joints very similar to those generated by inertial forces. The same operations were repeated for other values of RPM, and based on the results obtained it was possible to construct the shape of the load cycle to be applied on the fatigue stand.

The calculations results, displayed in Figs. 5 and 6, were used for the fatigue analysis, which was done with the nCode program. The analysis relied on the implementation of the results of FEM calculations for given boundary conditions, and on the implementation of a full load cycle (i.e. variability of static analysis results depending on the RPM time-profile assumed for the load cycle - see Fig. 7).

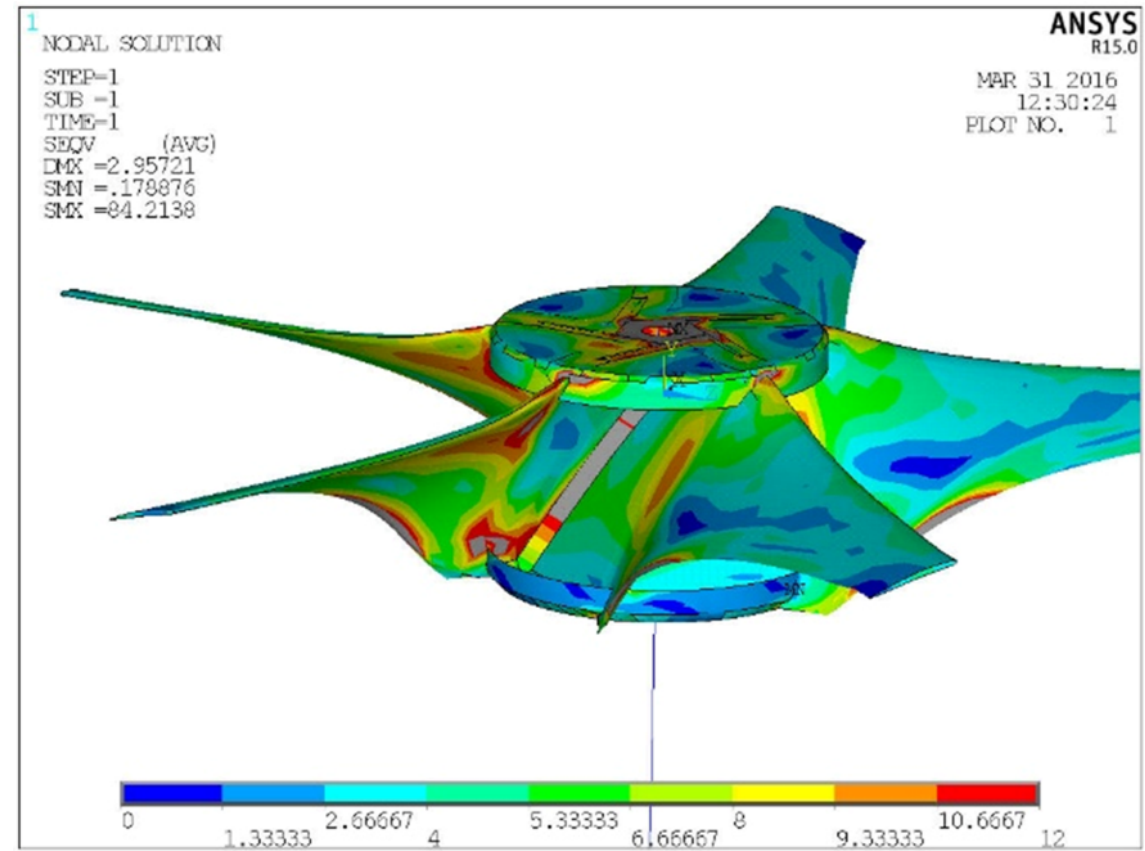

Fig. 5. Reduced stresses for inertial loading induced by rotational speed of $723 \mathrm{rad} / \mathrm{s}$

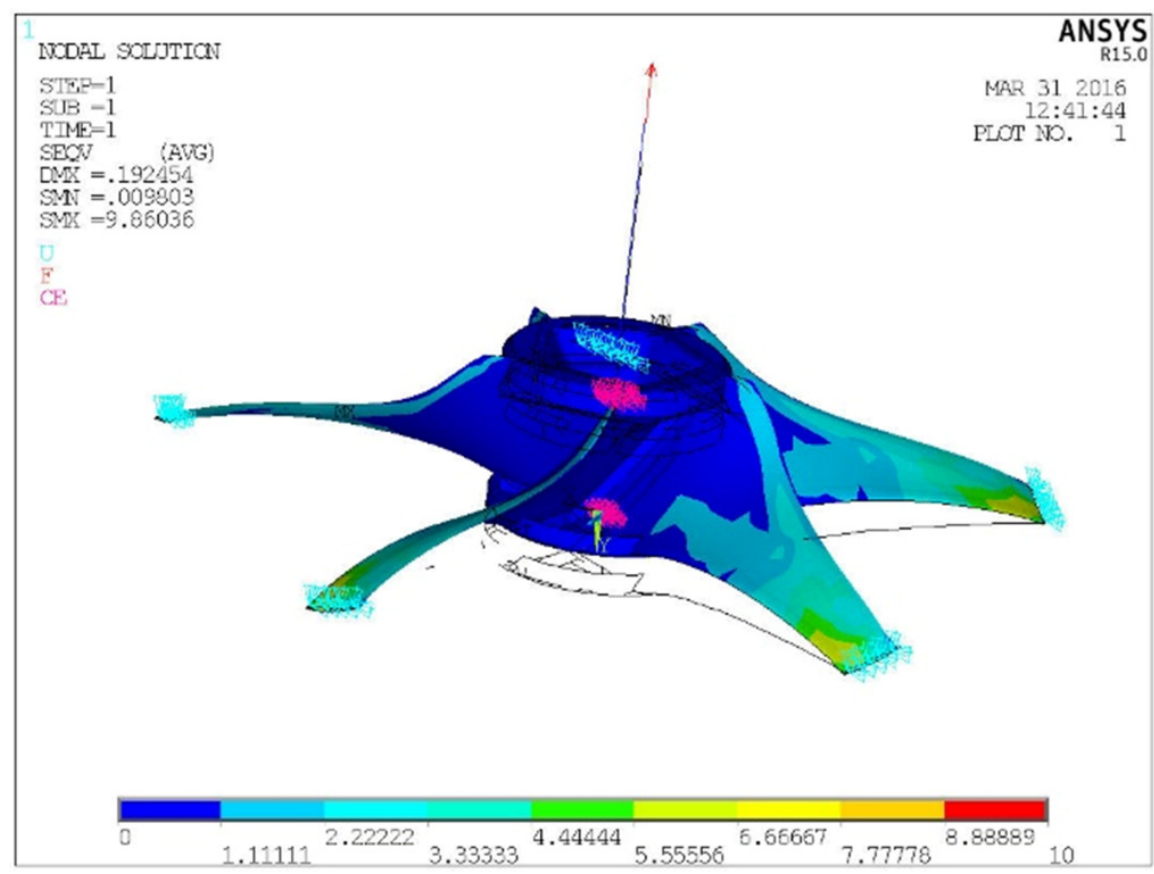

Fig. 6. Reduced stresses for loading by unitary force implemented at the central point of the hub 
The assumed load cycle included take-off, for which the rotor had 8000 RPM, and then the period of cruise flight, where rotor had 5000 RPM, then approach to landing with very low RPM, and the full RPM impulse just before touching the ground.

The nCode program used a built-in Palmgren-Miner fatigue model, which allowed estimating the maximal number of load cycles for chosen points of the glued joints between the blade and the hub (Fig. 8.).

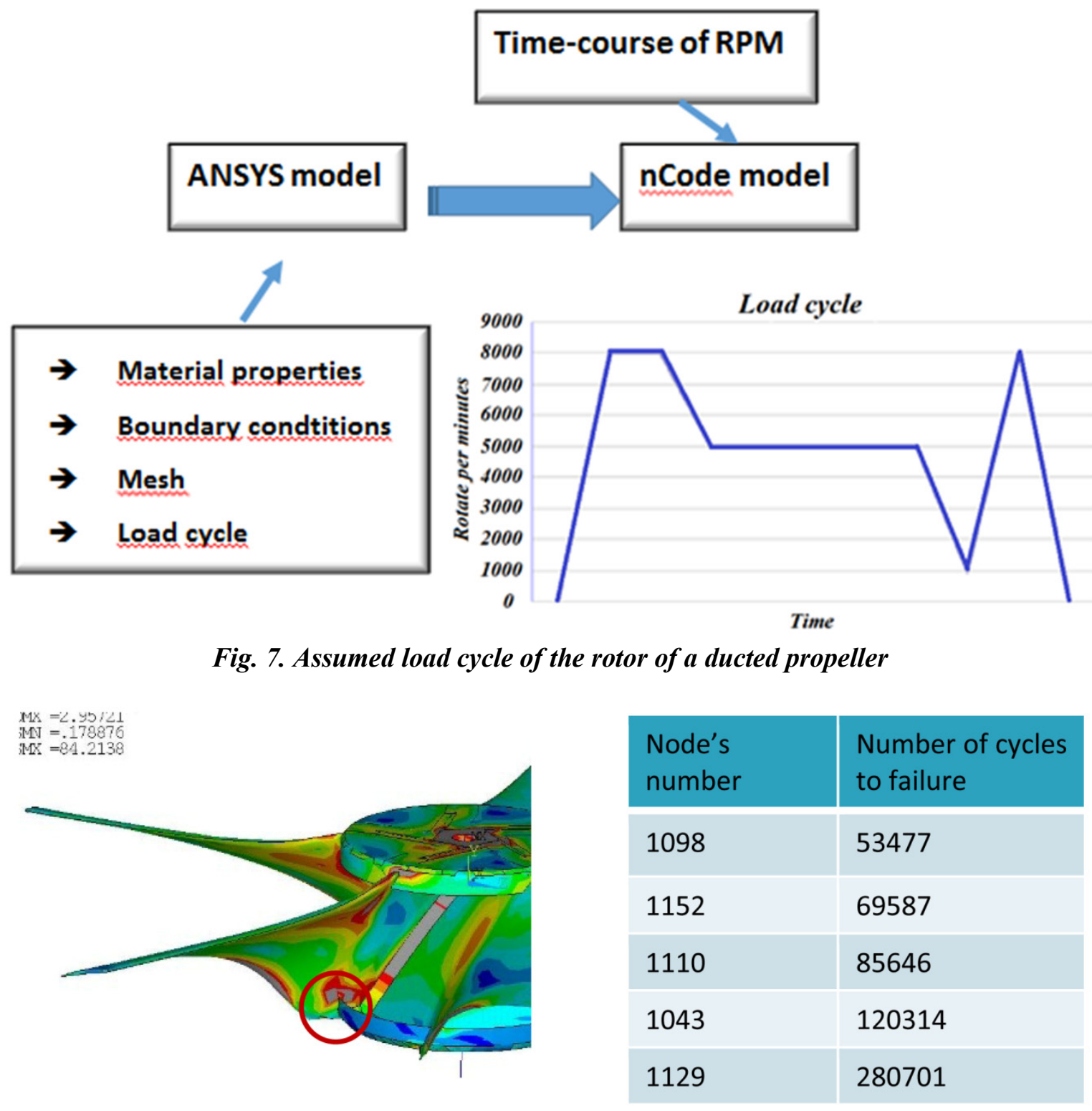

Fig. 8. Chosen node with highest risk of fatigue destruction

\section{THE CONCEPT OF THE METHOD OF EXPERIMENTAL INVESTIGATIONS}

Having prepared the numerical models and having obtained the provisional results from the fatigue analysis - the authors set out to prepare the stand for fatigue testing of the rotor. The concept of this stand is shown in figure 9.

The main element of the loading system was the pneumatic-electrical actuator which enables programming the steps of the load cycle and the velocity of the load changes. The pneumatic servo of this actuator is linked up with the rotor-specimen, which was fixed to the stiff aluminum car-rim (see Figs. 10 and 11). 


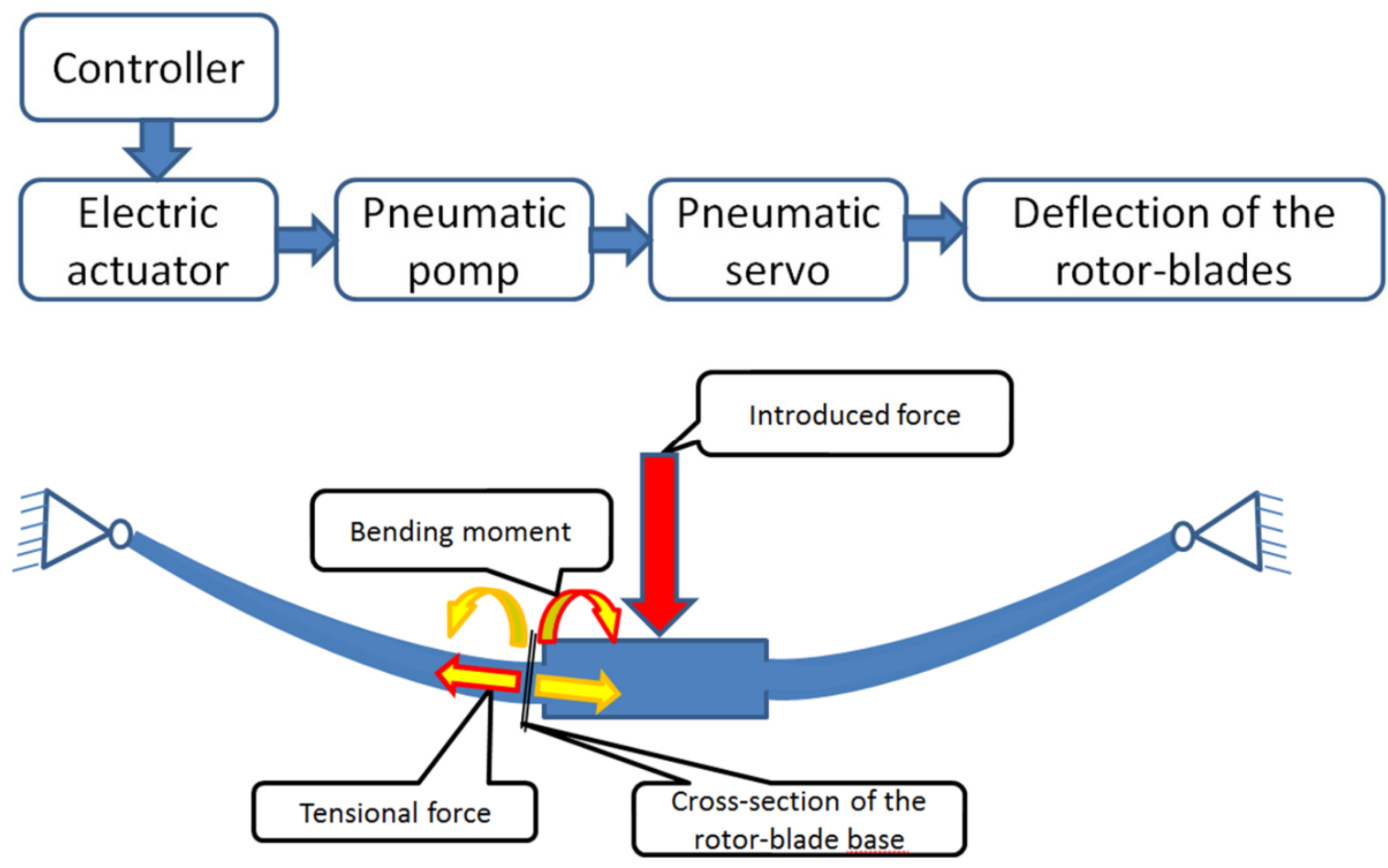

Fig. 9. The block-diagram of the fatigue stand
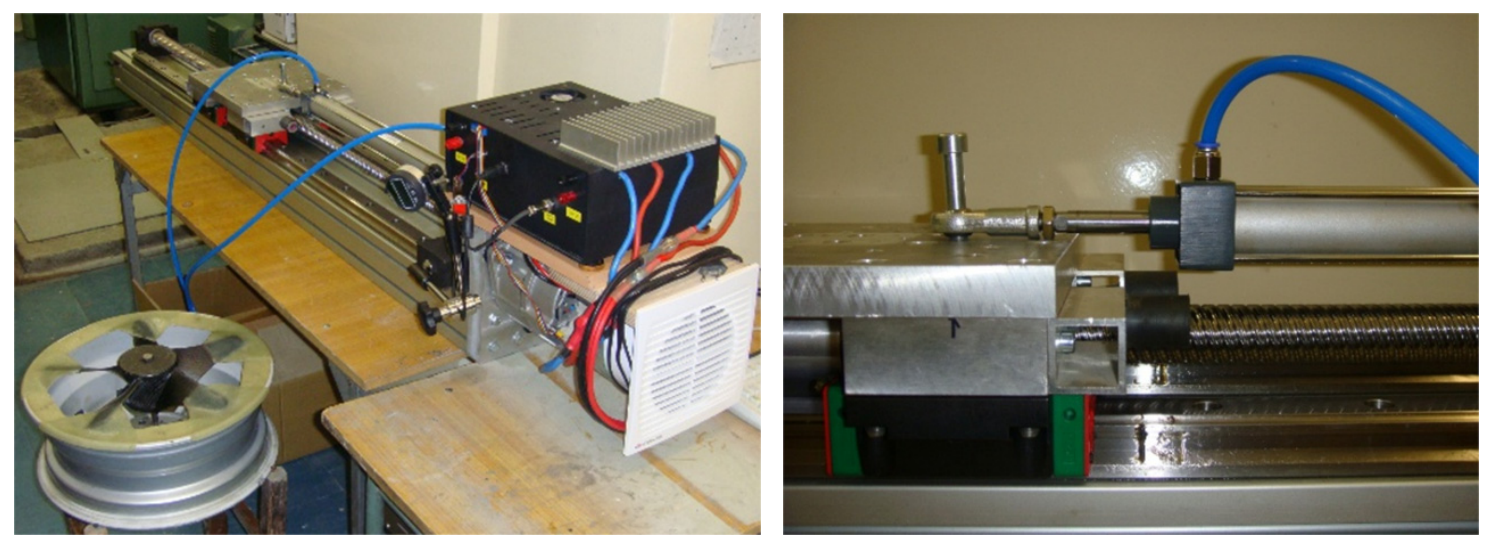

Fig. 10. Fatigue stand details
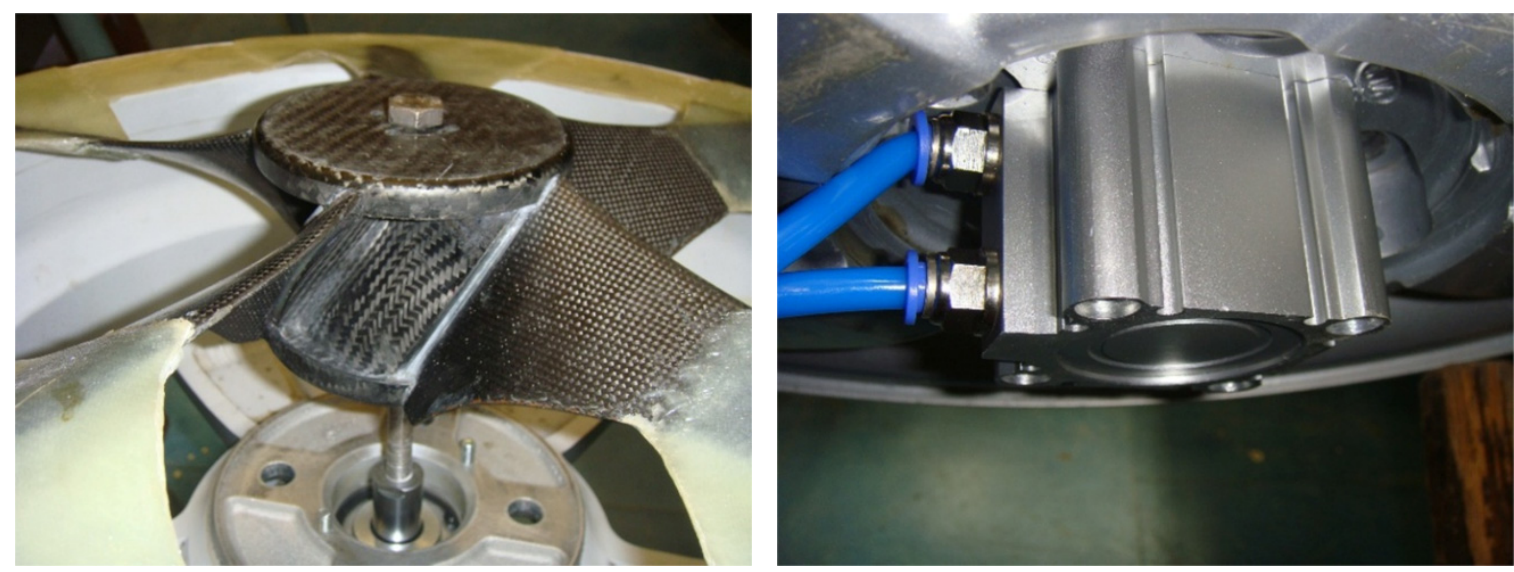

Fig. 11. Fatigue stand details 


\section{CONCLUSIONS}

The design of rotating elements of propulsion systems requires applying advanced calculation methods linked with the FEM. These methods enable taking into consideration the complex geometry of investigated elements. The paper presented a simplified method of fatigue testing of the rotor of the ducted propeller. Based on the calculations made by the authors one can conclude that the investigated rotor has sufficient fatigue durability within the range of normal operational loads. The authors conducted the tests aimed at experimental proving of fatigue life. The testing method proposed by the authors is relatively simple and does not require any sophisticated instrumentation.

\section{REFERENCES}

[1] Bogdanski K., Krusz W., Rodzewicz M. Rutkowski M. "Design and optimization of low speed ducted fan for a new generation of joined wing aircraft" ICAS 2014.

[2] Bogdański Krzysztof, Głowacki Dominik, Rodzewicz Mirosław: Research on the rotor of a ducted fan propulsion system of MOSUPS aircraft taking into account self balance during operation, w: Solid State Phenomena, Trans Tech Publications, vol. 240, 2016, pp. 191-197.

[3] Głowacki Dominik, Rodzewicz Mirosław: Badania dynamiczne wirnika napędu otunelowanego samolotu MOSUPS, w: Mechanika w Lotnictwie T I / Sibilski Krzysztof ( red. ), 2014, Polskie Towarzystwo Mechaniki Teoretycznej i Stosowanej, ISBN 978-83932107-3-2, ss. 49-63. 